Egyptian Journal of Aquatic Biology \& Fisheries

Zoology Department, Faculty of Science,

Ain Shams University, Cairo, Egypt.

ISSN $1110-6131$

Vol. 24(4): 267 - 280 (2020)

www.ejabf.journals.ekb.eg

\title{
Extracts of the green algae Ulva prolifera possess antioxidant and antibacterial activities in vitro
}

Mohamed S. M. Abd El Hafez ${ }^{1 *}$, Reham G. ElKomy ${ }^{1}$, Hosam Saleh ${ }^{2}$, and Haiam M. Aboul-Ela ${ }^{1}$

1-Marine Biotechnology Lab, Marine Environment Division, National Institute of Oceanography and Fisheries, NIOF, Egypt.

2-Fish Diseases Lab, Aquaculture Division, National Institute of Oceanography and Fisheries, NIOF, Egypt.

Corresponding Author: mohamedsaid80@yahoo.com

\section{ARTICLE INFO}

Article History:

Received: June 2, 2020

Accepted: June 20, 2020

Online: June 23, 2020

Keywords:

Phylogenetic analysis

Nutritional value

Antibacterial

Antioxidant

Ulva Prolifera

Red sea

\begin{abstract}
Macroalgae are currently being explored as novel and sustainable sources of bioactive compounds. Ulva prolifera is a major member of the green algae, as it includes various bioactive compounds, including carotenoids, fucoidans, and phlorotannins, with various biological activities in pharmaceutical, nutraceutical, cosmeceutical, and functional foods industries. In the current work, the $r b c \mathrm{~L}$ gene products were utilized in identifying $U$. prolifera molecularly. The antibacterial and antioxidant activities of the hexane, ethyl acetate, and methanol extracts of $U$. prolifera were carried out In vitro. The total antioxidant capacity method was utilized in assessing the antioxidant activity. Estimation of nutritional value of $U$. prolifera showed $5.4 \pm 0.04 \%, 1.7 \pm 0.04 \%$ and $43 \pm 0.5 \%$ dry weight for total proteins, lipids, and carbohydrates, respectively. The total antioxidant capacity of algal hexane, ethyl acetate, and methanol extract was $0.97 \pm 0.09,1.23 \pm 0.04$ and $1.63 \pm 0.09 \mathrm{mg}$ equivalent ascorbic acid/gdw, respectively. Investigation of the antibacterial activity of $U$. prolifera against Staphylococcus aureus and Aeromonas hydrophila showed that the recorded diameter of the inhibition zones for the methanolic extract was $1.1 \mathrm{~cm}$. The antibacterial effect of hexane extract against Edwardsiella tarda was high which had a diameter of $1.5 \mathrm{~cm}$. Of interest, the ethyl acetate extract of $U$. prolifera showed potent antibacterial activity against the three bacteria, including Vibrio anguillarum, Aeromonas hydrophila, and Edwardsiella tarda. These results indicate that macroalgae $U$. prolifera contain bioactive substances with potential antioxidant and antibacterial effects.
\end{abstract}

\section{INTRODUCTION}

Seaweeds or marine algae relate to a group of eukaryotes. Based on their nutrients, pigments, and chemical composition, seaweeds are divided into rhodophyta (red algae), phaeophyta (brown algae), or chlorophyta (green algae) (Princely and Dhanaraju, 2017). Similar to other types of plants, seaweeds include different organic and inorganic elements that are useful for human health and are considered as a source of 
secondary metabolites with a broad range of biological activities (Princely and Dhanaraju, 2017). Seaweeds or marine macroalgae are considered renewable living resources that are utilized as food and fertilizer in different parts around the world. Seaweeds are known for their nutritional benefit as being low calorie food as well as having vitamins, minerals, proteins, polysaccharides, and dietary fibers (Stirk et al., 2003 and Silva et al., 2013). In contrast, seaweeds contain limited amounts of unsaturated lipids that can protect against cardiovascular diseases.

Recent reports showed an inverse correlation between the dietary intake of foods rich in antioxidants and the occurrence of human diseases. Besides their nutritional benefit, seaweeds exert potent antioxidant activity due to its algae derived compounds like carotenoids, phenolics, terpenoids, and sulfated polysaccharides (ulvan, porphyran, alginate) demonstrate significant antioxidant activities (Shi $\boldsymbol{e t}$ al., 2017). In addition, its polysaccharides have been found to possess distinct immunomodulatory and anticancer effects (Chakraborty et al., 2015). The bioactive compounds in seaweeds and their secondary metabolites have also been reported to have a broad range of antimicrobial effects. Examples of these agents include chlorellin derivatives and halogenated compounds like polysaccharides, sulfate polysaccharides, peptides, proteins, vitamins, haloforms, halogenated alkanes and alkenes, alcohols, aldehydes, hydroquinones, sterols, ketones, and cyclic polysulfides (Cunha and Grenha, 2016). Many of these could be developed into antiseptics and cleansing agents, but their antibiotic activity is often only achieved in vivo at toxic concentrations (Radhika et al., 2014).

$U$. prolifera is a species of seaweed (phylum: Chlorophyta; class: Chlorophyceae; order: Ulvales; family: Ulvaceae; genus: Ulva). It is an important producer of a broad range of natural substances like carotenoids, fucoidans, and phlorotannins. Those compounds have various biological activities in pharmaceutical, nutraceutical, cosmeceutical, and functional foods industries (Zeng et al., 1962 and Hayden et al., 2003). The $r b c \mathrm{~L}$ gene is identified as a relatively short piece of DNA which can be easily amplified and sequenced with a single set of primers. (Saunders, 2005) show evidence that identifying species of algae can be executed through the use of $r b c \mathrm{~L}$ gene.

The importance of these compounds had significantly increased with the new discoveries of their potentials and pharmaceutical activities as: anticancer, antimicrobials, antivirals, anti-inflammatories and other medical advantages (Shi et al., 2017; Praiboon et al., 2017 and Mohan et al., 2019). The antimicrobial activities of green macroalgal extracts had been proved against many gram positive and gram negative microorganisms as: Staphylococcus aureus, Bacillus subtilis, Escherichia coli, Pseudomonas aeruginosa, Salmonella typhi, Staphylococcus epidermidis, Klebsiella spp (Alghazeer et al., 2013), Bacillus pumulis and Enterococcus faecalis (Mashjoor et al., 2018).

Macroalgae are resistance to the oxidative effects of reactive oxygen species (ROS) upon their exposure to both light and oxygen due to their protective antioxidative defense systems in their cells (Fujimoto, 1990 and Matsukawa et al., 1997), including protective enzymes (e.g., superoxide dismutase, peroxidase, glutathione reductase, and catalase) as well as antioxidative molecules (e.g., carotenoids, ascorbic acid, phlorotannins, tocopherols, phospholipids, chlorophyll related compounds, bromophenols, catechins, mycosporine like amino acids, and polysaccharides), which resemble those of vascular plants (Rupérez et al., 2002 and Yuan et al., 2005). 
ROS, which cause oxidative damage, results in the development of different chronic disease states such as coronary heart disease, cancer, diabetes, rheumatoid arthritis, chronic inflammatory disease of the gastrointestinal tract, Alzheimer's disease, and other neurological disorders related to the aging processes (Temple, 2000; Chauhan and Chauhan, 2006).

The results of the present study conclude that macroalgae $U$. prolifera, collected from the Egyptian Red Sea, have potential bioactive substances with both antioxidant and antibacterial effects and could be used as healthy valuable edible seaweed.

\section{MATERIALS AND METHODS}

\section{Sampling Location and Algal Collection}

The green algae, $U$. prolifera, were collected in June 2019 at a depth of 1-2 m from the water surface during low tide at Hurghada, Egypt (latitude: $27.28^{\circ} \mathrm{N}$ and longitude: $33.77^{\circ} \mathrm{E}$ ) (Figure 1). Seawater was used in cleaning the collected algae in order to get rid of all extraneous matter like epiphytes, sand particles, pebbles, and shells. We brought those algae to the laboratory in plastic bags. The marine algae were then thoroughly rinsed and washed with sterile water, blotted, and spread out at room temperature $\left(25^{\circ} \mathrm{C}\right)$ for drying. The $r b c \mathrm{~L}$ gene products were utilized in identifying the algae molecularly.

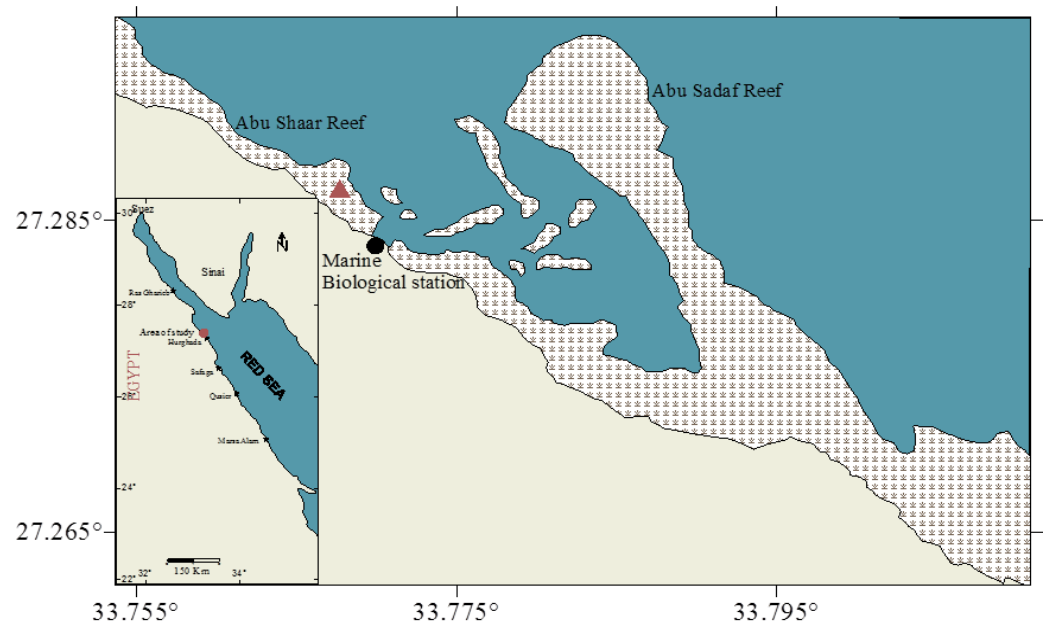

Fig. 1: Samples collection area; Red Sea, Hurghada

\section{Preparation of the Algal Sample Extracts}

Upon collection and cleaning of the samples, they were immediately transferred to the laboratory for extraction (figure 2). Algae were dried and ground to obtain a fine powder. The quantity of the solvents used was twice the weight of the specimens. Hexane, ethyl acetate, and methanol were the solvents used for the extraction at room temperature. Extraction was done by soaking the dried powder in the solvent for a week at room temperature, the mixture was filtered through the use of Whatman No. 1 filter paper, and the obtained filtrates were concentrated via rotary evaporator (Stuart RE300) at $40^{\circ} \mathrm{C}$ under reduced pressure. The resultant residue was kept frozen at $-20^{\circ} \mathrm{C}$ for later analysis of antibacterial and antioxidant activities (Nagaraj et al., 2014). 


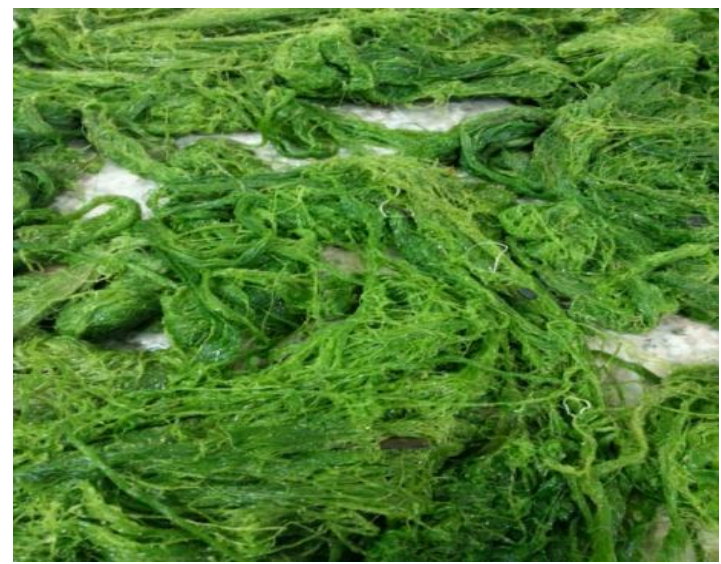

Fig. 2: The green algae, coded HMR01, used in the present study

\section{DNA Extraction, PCR Amplification and Sequencing}

Total DNA was derived from $50 \mathrm{mg}$ of the fresh algal sample tissue in about $1 \mathrm{ml}$ TriFast as per the manufacturer's protocol (Peqlab, VWR Company). The isolation method is based on the well-known single step liquid phase separation (Chomczynski, 1993). Extracted DNA was purified further, following a single isopropanol precipitation, by GFX PCR DNA purification kit (Amersham Biosciences, USA) as per the manufacturer's protocols.

Ribulose bisphosphate carboxylase gene $(r b c \mathrm{~L})$ gene was amplified via GeneAmp Polymerase Chain Reaction (Creacon, Thermocycler, Holand) system cycler. PCR for amplified genomic DNA was done via $r b c \mathrm{~L}$ gene specific primers ( 1320 bp); rbcLF - 5' TGTTTACGAGGTGGTCTTGA 3'and $r b c L$ R - 5' TCAAGACCACCTCGTAAACA 3'. PCR reaction for $r b c \mathrm{~L}$ gene $(50 \mu \mathrm{l})$ was carried out under certain cycling conditions as follows: initial denaturation at $94^{\circ} \mathrm{C}$ for $5 \mathrm{~min}$, then $1 \mathrm{~min}$ at $94^{\circ} \mathrm{C}$ and $3 \mathrm{~min}$ at $60^{\circ} \mathrm{C}$ for 30 cycles, and a final 10 min extension at $60^{\circ} \mathrm{C}$ (Blomster et al., 1998). Resultant PCR products were purified with E.Z.N.A. ${ }^{\circledR}$ Gel Extraction Kit (D2500-01, Omega BIO-TEK, USA). Sequencing was employed using the ABI PRISM ${ }^{\circledR} 3100$ Genetic Analyzer (Micron-Corp., Korea).

\section{Data Analysis, Alignments and Phylogenetic Analysis}

Gel documentation system (Geldoc-it, UVP, England) was used for analyzing the obtained data through Totallab analysis software (www.totallab.com) (Ver.1.0.1). Aligned sequences were analyzed on NCBI website (http://www.ncbi.nlm.nih. gov/webcite) using BLAST to confirm their identity. Genetic distances and MultiAlignments were computed via pairwise distance method using Clustal Omega software analysis (https://www.ebi.ac.uk/Tools/msa/clustalo/). The nucleotide sequences were also compared with the highest homology sequences available in the GenBank. Sequences were aligned, the maximum likelihood (ML) was analyzed, and phylogenetic tree was visualized through the MEGA7 program (Kumar et al., 2016).

\section{Measuring the total proteins, carbohydrates and lipids of algae}

Tris-HCL buffer (0.1 M pH 7.5) was used in extracting the dry seaweeds elements overnight at $4^{\circ} \mathrm{C}$ with stirring. Following centrifugation, the estimation of the total 
amount of protein in the supernatant was spectrophotometrically carried out at $750 \mathrm{~nm}$ (Lowry et al., 1951) with the bovine serum albumin which was utilized as a standard. Proteins were identified as percentage of algal dry weight.

The estimation of the total carbohydrates was done according to the phenolsulfuric acid method of (Dubois et al., 1956), following extraction with 2.5 N HCL for $3 \mathrm{~h}$ at $100^{\circ} \mathrm{C}$. The calculation of the content was carried out in percentage with reference to the glucose standard curve.

The extraction of lipids was done according to a chloroform-methanol method (Bligh and Dyer, 1959), and the results were expressed in percentage. The lipids in chloroform were left to dry over anhydrous sodium sulfate, after which we got rid of the solvent by heating at $80^{\circ} \mathrm{C}$ under vacuum.

\section{Determination of the antibacterial activity}

The hexane, ethyl acetate, and methanolic extract of $U$. prolifera were tested against different bacterial pathogens for their antibacterial activity. We dissolved the condensed extracts in 4\% DMSO4 (dimethyl sulfoxide). The well diffusion method was utilized in testing the antibacterial activity of the algal extracts (Bauer et al., 1996). The inoculation of the prepared culture plates was employed using different selected bacterial strains through streak plate method. Moreover, the wells were implemented on the surface of the agar using a $6 \mathrm{~mm}$ cork borer. We poured the extracts into the well with the use of sterile syringe. Prediffusion was done for $3 \mathrm{~h}$ at $10^{\circ} \mathrm{C}$ (Bansemir et al., 2006). The calculation of the inhibition zone was performed through measuring the inhibition zone diameter around the well (in $\mathrm{cm}$ ) as well as the well diameter. In all 3 replicates, the readings were obtained from three different fixed directions, and the average values were tabulated. The measurement of the inhibition zones was employed after an incubation period that lasted for $24 \mathrm{~h}$ at $37^{\circ} \mathrm{C}$ for bacteria (Attaie et al., 1987).

The antibacterial activity was determined against one gram positive bacteria: (Staphylococcus aureus) and six gram negative bacteria: (Salmonella spp., Vibrio angullarum, Aeromonas hydrophila, Pseudomonas aeruginosa, Escherichia coli and Edwarsiella tarda). These tested bacteria were obtained from Microbiology Lab., National Institute of Oceanography and Fisheries, NIOF, Alexandria, Egypt.

\section{Determination of Total Antioxidant Capacity}

The total antioxidant capacity (TAC) was measured using different solvents following the protocol of (Prieto et al., 1999). TAC reagent was prepared through a mixture of sulfuric acid $(0.6 \mathrm{M})$, sodium phosphate $(28 \mathrm{mM})$, and ammonium molybdate $(4 \mathrm{mM})$ with distilled water. Then, $3 \mathrm{ml}$ of algae extract was added to $3 \mathrm{ml}$ of TAC reagent and incubated at $95^{\circ} \mathrm{C}$ for $90 \mathrm{~min}$. T70 spectrophotometer (PG Instruments, UK) was utilized for measuring the absorbance at $695 \mathrm{~nm}$. Total antioxidant capacity was determined as a percentage with standard that is represented with ascorbic acid. Total antioxidant capacity $(\mathrm{TAC}) \%=[(\mathrm{Ac}-\mathrm{As}) / \mathrm{Ac}] \times 100$, where Ac is the control absorbance and As is the sample absorbance. 


\section{Statistical Analysis}

All the experiments were conducted in triplicate. Statistical differences detected between the activities of three extracts were identified through the use of one-way ANOVA. Statistically significant differences were determined when $p<0.05$.

\section{RESULTS}

\section{Taxonomic Identification of the Algal Sample using $r b c L$ Gene Analysis}

The algal sample was identified by a molecular approach. $r b c \mathrm{~L}$ gene was amplified and purified through the use of specific primers in order to process the phylogenetic analysis. The results (Figure 3) indicated that the $r b c \mathrm{~L}$ gene belonged mainly to the green algae of Ulva genus (Ulvaceae, Chlorophyta).

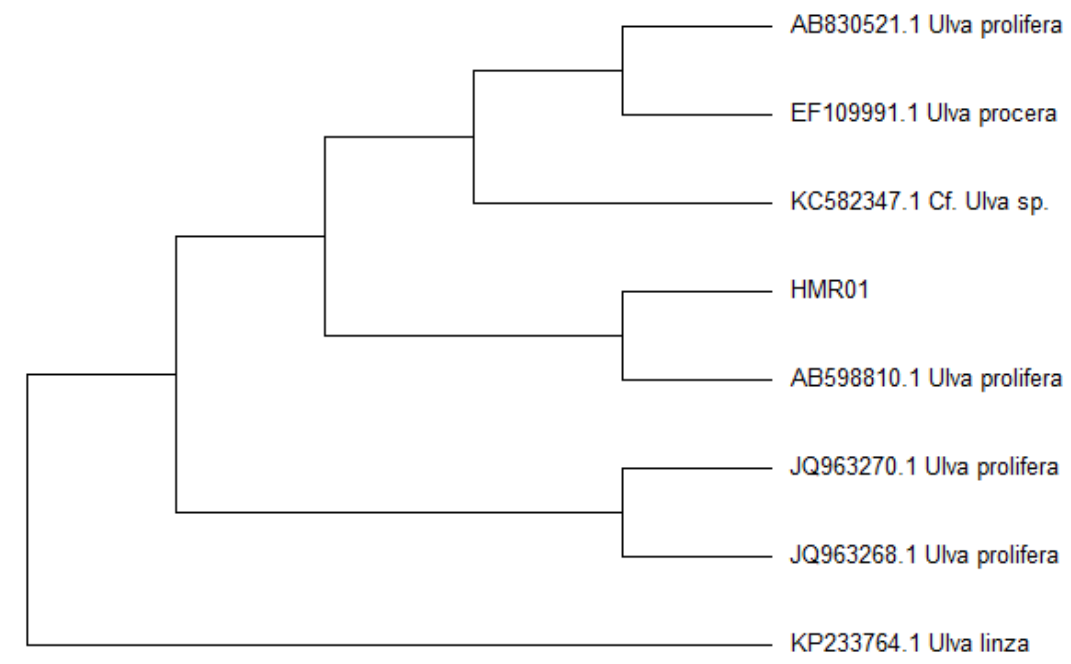

Fig. 3: A Maximum likelihood phylogenetic tree (ML tree) of the green algal sample HMR01 under the current investigation inferred from the $r b c \mathrm{~L}$ gene sequences.

\section{$U$. prolifera contains components with potential nutritional value}

Estimation of the nutritional value of the algal sample showed $5.4 \pm 0.04 \%$, $1.7 \pm 0.04 \%$ and $43 \pm 0.5 \%$ dry weight for total proteins, total lipids and total carbohydrates, respectively, as shown in Figure (4).

\section{Extracts of $\boldsymbol{U}$. prolifera exert antibacterial activities}

The results of the inhibitory activity of the three solvent extracts of the macroalgae $U$. prolifera against pathogenic bacteria are summarized in Table (1). The methanol extract of $U$. prolifera showed activity against most of the tested bacteria; the diameter of inhibition zones recorded $1.1 \mathrm{~cm}$ for Staphylococcus aureus and Aeromonas hydrophila as shown in figure (5). However, the hexane extract showed higher activity against Edwarsiella tarda; the recorded diameter was $1.5 \mathrm{~cm}$. The ethyl acetate extract showed more activity against Vibrio angullarum, Aeromonas hydrophila and Edwarsiella tarda; the recorded diameters were $1.4 \mathrm{~cm}, 1.3 \mathrm{~cm}$ and $0.9 \mathrm{~cm}$, respectively. On the other hand, the hexane and ethyl acetate extracts did not exhibit any activity against Staphylococcus aureus, Salmonella spp., Pseudomonas aeruginosa and Escherichia coli. 


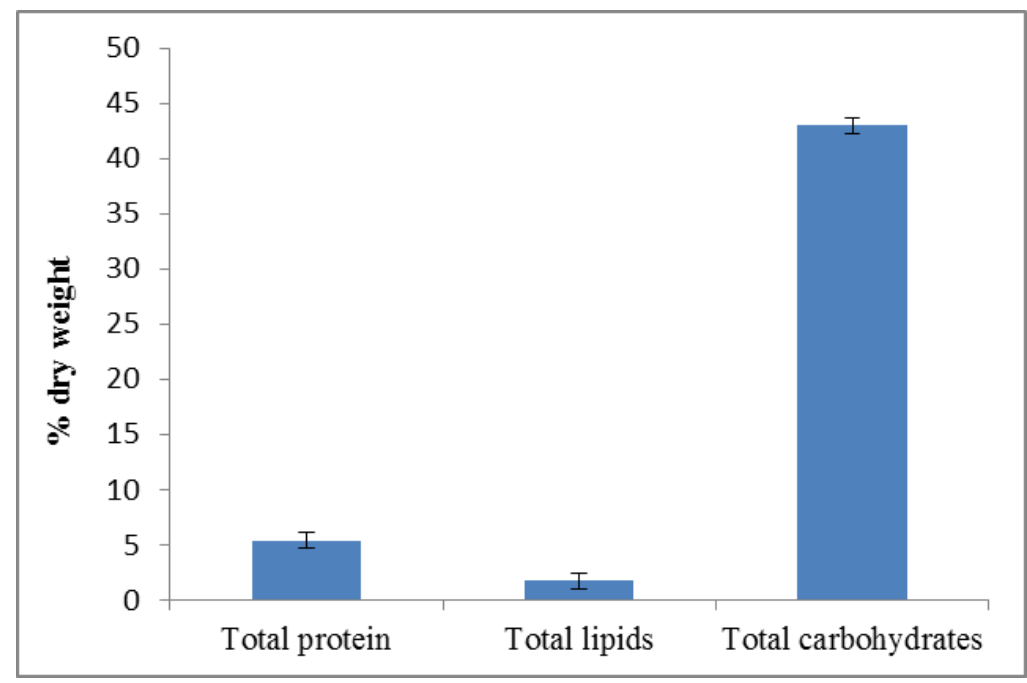

Fig. 4: Nutritional value of the algal sample, each value is expressed as the mean \pm SD

Table (1): Antibacterial activity of the investigated hexane, ethyl acetate and methanol extracts of green macroalgae $U$. prolifera using the agar plate diffusion assay

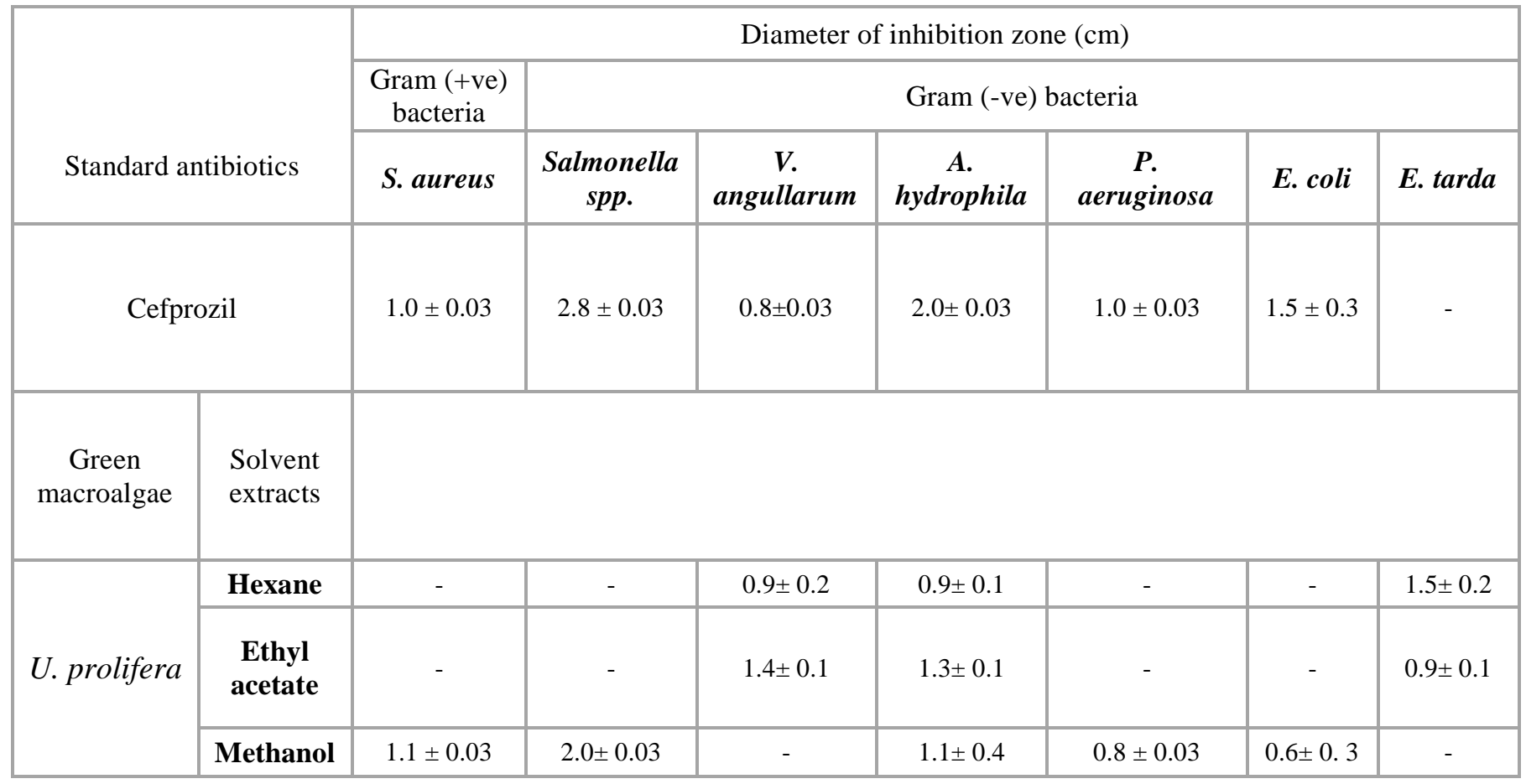

[- = No inhibitory effect; width 0.1 to $0.8 \mathrm{~cm}=$ week activity; width 0.8 to $1.0 \mathrm{~cm}=$ moderate activities; width $>1.0 \mathrm{~cm}=$ strong activity. Data are expressed as mean $\pm \mathrm{SD}$ ] 

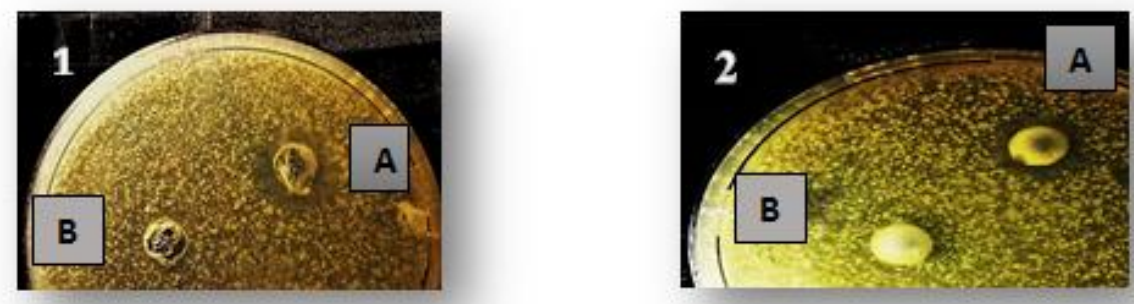

Fig. 5: (A) The inhibition zone against Aeromonas hydrophila (using methanol extract in photo 1 and ethylacetate extract in photo 2), whereas (B) shows the negative control.

\section{Extracts of $\boldsymbol{U}$. prolifera exerts antioxidant activity}

The algal hexane, ethylacetate and methanol extracts indicated a total antioxidant capacity of $0.97 \pm 0.09,1.23 \pm 0.04$ and $1.63 \pm 0.09 \mathrm{mg}$ equivalent ascorbic acid /gdw, respectively, as shown in figure (6).

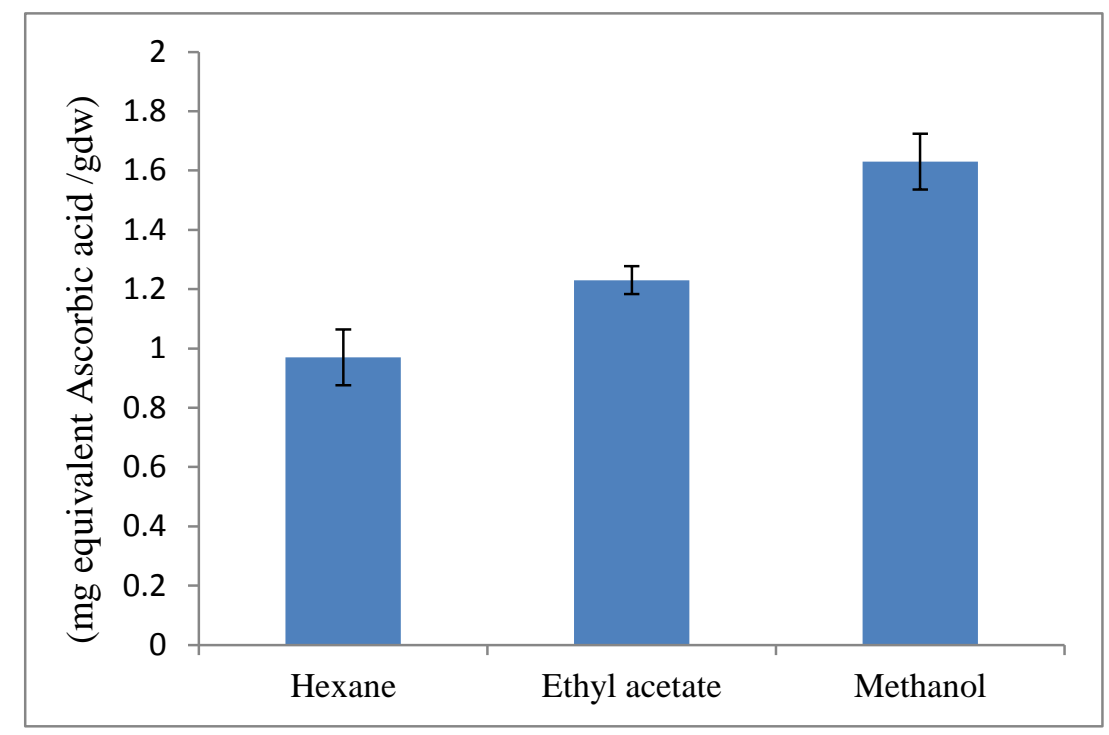

Fig. 6: Total antioxidant capacity (TAC) for different algae extracts.

\section{DISCUSSION}

With the main goal to explore new natural sources with antioxidant and antibacterial activities, the present study was designed to evaluate these activities for the algae $U$. prolifera, The data revealed three main findings for this seaweed: 1) it is with nutritional values since it contains polysaccharides, lipids and proteins, 2) it possesses potent antioxidant activities, and 3) it has potent antibacterial effects against gram negative and gram positive bacteria. These results together indicate the biological importance of this alga in particular in industrial applications.

The phylogenetic analysis confirmed that this algal sample collected from the seashore of Hurghada, Egypt was $U$. prolifera at the species level. We used the 
technology of the gene sequencing of $r b c \mathrm{~L}$ gene as a powerful marker used in DNA barcoding. The $r b c \mathrm{~L}$ gene is identified as a relatively short piece of DNA which can be easily amplified and sequenced with a single set of primers. Indeed, the use of $r b c \mathrm{~L}$ provides evidence for identification of the species of algae (Saunders, 2005). In addition, potential incipient speciation seems to be disclosed through using $r b c \mathrm{~L}$, as shown by the data for both Mastocarpus stellatus and Porphyra umbilicalis. Interestingly, the protein coding in $r b c \mathrm{~L}$ gene proved also to be useful for identifying algae species.

The evolutionary history of $U$. prolifera is in line with what was concluded based on the use of the maximum likelihood method depending on the Tamura-Nei model (Tamura and Nei, 1993), where the tree that has the highest log likelihood (-559.6260) is indicated. The initial tree(s) for the heuristic search were acquired automatically through employing Neighbor-Join as well as BioNJ algorithms to a matrix of pairwise distances that were estimated via the approach of maximum composite likelihood (MCL) followed by choosing the topology with superior log likelihood value. Nine nucleotide sequences were involved in our analysis. The included codon positions were $1 \mathrm{st}+2 \mathrm{nd}+3 \mathrm{rd}+$ noncoding. Sixty positions in total were in the final dataset. Evolutionary analyses were carried out through the use of MEGA7 program (Kumar et al., 2016).

The macroalgae have nutritional properties which are normally estimated for their chemical structure (Darcy Vrillon, 1993). Previous reports demonstrated that the macroalgae have different chemical composition based on the geographical distribution, habitats, maturity, seasons, and principal environmental conditions like water temperature, salinity, light, and nutrients (Kaimoussi et al., 2004; Ortiz et al., 2006; Messyasz and Rybak, 2010). In addition, Ulva morphology is greatly affected by the age of the thallus, lifestyle, environmental conditions, and nutrient concentrations in their habitats, making it is difficult to recognize the species solely by their morphological features alone (Messyasz and Rybak, 2010).

Generally, it is reported that the macroalgae have lipid content less than 5\% of dry weight (Khairy and El-Shafay, 2013). Even so, some macroalgae at different locations showed higher lipid content. However, with the increase in temperature, a decrease in the lipid content occurred and it remained almost unchanged until the end of the growing season. The differences in the reported quantities of the lipids extracted could have been due to many factors such as geographical and seasonal factors, or climate change as well as the development stage of the macroalgae as demonstrated by Ortiz et al. (2006). In this study, the algal sample showed $1.7 \pm 0.04 \%$ dry weight for total lipids, and this confirms what reported by (Khairy and El-Shafay, 2013).

According to Ratana-arporn and Chirapart (2006), the differences among the macroalgae species along with the seasonal period have a vital role in the variation of the algae protein content. Lectins are of the essential bioactive proteins which can be derived from macroalgae; they bind to carbohydrates and take part in various biological processes such as intercellular communication. Those bioactive proteins are also characterized by antibacterial, antiviral, or anti-inflammatory activities (Cunningham, 2010). The functional properties are the responsibility of the various types of polysaccharides that exist in seaweeds, and the chemical composition of those polysaccharides belongs to the corresponding taxonomic classification of algae and their cell structure. Many of them are soluble dietary fibers which affect the digestive track of animals positively (i.e., alginic acid). The soluble polysaccharides that are extracted from seaweeds are more effective 
and nontoxic antioxidants. The contents of polysaccharides differ based on the climatic conditions. The sulfated galactans, fucoidan, laminarin, and alginates are the major bioactive compounds among the numerous algal polysaccharides (Ferreira, 2012). In this study, the algal sample showed $5.4 \pm 0.04 \%, 43 \pm 0.5 \%$ dry weight for total proteins and total carbohydrates, respectively. These variations in the content of algal proteins and carbohydrates among other algal species could have been due to several factors such as, geographical and seasonal factors, or climate change as well as the algae development stage as reported by Ortiz et al. (2006).

Seaweeds spread widely in the marine environment; there are many types of seaweed that are reported to have antibacterial activity (Nagaraj et al., 2014). Rajauria et al. (2013) reported that, among the different concentrations of methanol, there were significant variations in the extraction yield as well as the antimicrobial activity, with $60 \%$ methanol allowing optimal performance from $H$. elongata. A number of studies reported that methanol was more effective (Pierre et al., 2011; Adaikalaraj et al., 2012 and Al Hazzani et al., 2014). The higher antibacterial activity of the polar extracts was confirmed by other works (Pierre et al., 2011 and De Jesus Raposo et al., 2015). The findings of this experiments are similar to those of previous studies (Osman et al. 2010; Oumaskour et al., 2012and Ali et al., 2016). The different families of seaweed were compared by various authors regarding their antibacterial activity (Cox et al., 2010; Osman et al., 2010 and Al Hazzani et al., 2014).

Marine organisms have been exposed to different environmental changes and stresses over time; yet they managed to develop complex antioxidant defense mechanisms through which they were able to regulate homeostasis under these stresses, which protected them against cellular damage. Antioxidants are necessary inhibitors against ROS and lipid peroxidation; thus, those compounds are used to delay or prevent lipid peroxidation in foods and oxidation of cellular substrates. Their effects appear through scavenging ROS, activating detoxifying proteins, or stopping the generation of free radicals (Yang et al., 2019). With this features of marine algae, they are a main source for effective antioxidants agents against oxidative stress in human body because of the presence of various natural products that have unique structures (Yang et al., 2019).

\section{CONCLUSION}

The present work reveled that this algal species could be considered as a source of bioactive compounds with antioxidant and antibacterial effects. Moreover, estimation of its nutritional parameters as carbohydrates, proteins, lipids, revealed that the green algae, Ulva prolifera, is a potential and promising source of valuable nutritional components from mariculturing for its use as edible seaweed.

\section{REFERENCES}

Adaikalaraj, G.; Patric, R.D.; Johnson, M.; Janakiraman, N. and Babu, A. (2012). Antibacterial potential of selected red seaweeds from Manapad coastal areas, Thoothukudi, Tamil Nadu, India. Asian Pac. J. Trop. Biomed., 2:1077-1080. https://doi.org/10.1016/S2221-1691(12)60364-5. 
Alghazeer, R.; Whida, F.; Abduelrhman, E.; Gammoudi, F. and Azwai, S. (2013). Screening of antibacterial activity in marine green, red and brown macroalgae from the western coast of Libya. Nat. Sci., 5 (1):7-14.

Al Hazzani, A.A.; Shehata, A.I.; Moubayed, N.M.S. and Al Houri, H.J. (2014). Antimicrobial and biochemical properties of selected edible brown and red marine macroalgae. J. Pure Appl. Microbiol., 8:1275-1282.

Ali, S.S.; Shaaban, M.T.; Abohmora, A.E.F. and El-Safity, K. (2016). Macroalgal activity against multiple drug resistant Aeromonas hydrophila: A novel treatment study towards enhancement of fish growth performance. Microbial Pathogenesis., 101: 8995. https://doi.org/10.1016/j.micpath.2016.10.026.

Attaie, R. J.; Whalen, K. M. and Arner, M. A. (1987). Inhibition of growth of S. aureus during production of acidophilus yogurt. J. Food Protec., 50: 224- 228. https://doi.org/10.4315/0362-028X-50.3.224.

Bansemir, A.; Blume, M.; Schröder, S.U. and Lindequist, U. (2006). Screening of cultivated seaweeds for antibacterial activity against fish pathogenic bacteria. Aquaculture., 252: 79-4. https://doi.org/10.1016/j.aquaculture.2005.11.051.

Bauer, A.W.; Kirby, W. M. M.; Truck, H. and Shrecies, J. C. (1996). Antibiotic susceptibility testing by standardized single disc method. Am. J. Clin. Pathol., 45: 493-496.

Bligh, E.G. and Dyer, W.J. (1959). A rapid method of total lipid extraction and purification. Can. J. Biochem. Physiol., 37:911-7.

Blomster, J.; Maggs, C.A. and Stanhope, M.J. (1998). Molecular and Morphological Analysis of Enteromorpha Intestinalis and E. Compressa (chlorophyta) in the British Isles. J. Phycology, 34:319-340. https://doi.org/10.1046/j.1529-8817.1998.340319.x.

Chakraborty, K.; Joseph, D. and Praveen, K. (2015). Antioxidant activities and phenolic contents of three red seaweeds (division: Rhodophyta) harvested from the Gulf of Mannar of Peninsular India. J. Food Sci. Technol., 52(4):1924-35.

Chauhan, V. and Chauhan, A. (2006). Oxidative stress in Alzheimer's disease. Pathophysiology., 13:195-208.

Chomczynski, P. (1993). A reagent for the single-step simultaneous isolation of RNA, DNA and proteins from cell and tissue samples. Biotechniques., 15(3):532-4, 536-7. https://www.altmetric.com/details/4509567.

Cox, S.; Abu-Ghannam, N. and Gupta, S. (2010). An assessment of the antioxidant and antimicrobial activity of six species of edible Irish seaweeds. Int. Food Res. J., 17:205-220.

Cunha, L. and Grenha, A. (2016). Sulfated seaweed polysaccharides as multifunctional materials in drug delivery applications. Mar. Drugs., 14:1-41. https://doi.org/ 10.3390 /md14030042.

Cunningham, S. and Joshi, L. (2010). In: "Transgenic crop plants.” Kole, C. (Ed.). Berlin, Heidelberg: Springer Verlag, pp. 343-357. https://doi.org/10.1007/978-3-642-048128.

Darcy-Vrillon, B. (1993). Nutritional aspects of the developing use of marine macroalgae for the human industry. Int. J. Food Sci. Nutrition, 44:23-35. http://pascalfrancis.inist.fr/vibad/index.php?action=getRecordDetail\&idt=4032716. 
De Jesus Raposo, M.F.; de Morais, A.M.B. and de Morais, R.M.S.C. (2015). Marine polysaccharides from algae with potential biomedical applications. Mar. Drugs., 13:2967-3028. https://doi.org/10.3390/md13052967.

Dubois, M.; Gilles, K.; Hamilton, J.; Rebers, P. and Smith, F. (1956). Colorimetric method for determination of sugars and related substances. Anal. Chem., 28(3):350-356. https://doi.org/10.1021/ac60111a017.

Ferreira, L.G.; Noseda, M.D. and Goncalves, A.G. (2012). Chemical structure of the complex pyruvylated and sulfated agaran from the red seaweed Palisada flag-ellifera (Ceramiales, Rhodophyta). Carbohydr. Res., 347: 83-94. https://doi.org/10.1016/j.carres.2011.10.007.

Fujimoto, K. (1990). Antioxidant activity of algal extracts. In: "Introduction to applied phycology." Akatsuka, I. (Ed.). SPB Academic Publishing, The Hague, pp. 199-208.

Hayden, H.; Blomster, J. and Maggs, C. (2003). Linnaeus was right all along: Ulva and enteromorpha are not distinct genera. Eur. J. Phycol., 38: 277-294. https://doi.org/10.1080/1364253031000136321.

Kaimoussi, A.; Mouzdahir, A. and Saih, A. (2004). Variations saisonnières des teneurs en métaux $(\mathrm{Cd}, \mathrm{Cu}, \mathrm{Fe}, \mathrm{Mn}$ et $\mathrm{Zn})$ chez l'algue Ulva lactuca prélevée au niveau du littoral de la ville d'El Jadida (Maroc). Comptes Rendus Biologies, 327:361-369. https://doi.org/10.1016/j.crvi.2004.01.007.

Khairy, H.M. and El-Shafay, S.M. (2013). Seasonal variations in the biochemical composition of some common macroalgae species from the coast of Abu Qir Bay, Alexandria, Egypt. Oceanologia, 55(2):435-452. https://doi.org/10.5697/oc.55-2.435.

Kumar, S.; Stecher, G. and Tamura, K. (2016). MEGA7: Molecular Evolutionary Genetics Analysis version 7.0 for bigger datasets. Mol. Biol. Evol., 33(7):1870-4. https://doi.org/10.1093/molbev/msw054.

Lowry, O.H.; Rosenbrough, N.J.; Farr, A.L. and Randall, R.J. (1951). Protein measurement with the Folin phenol reagent. J. Biol. Chem., 193:265-275.

Mashjoor, S.; Yousefzadi, M.; Zolgharnain, H.; Kamrani, E. and Alishahi, M. (2018). Organic and inorganic nano-Fe3O4: Alga Ulva flexuosa-based synthesis, antimicrobial effects and acute toxicity to briny water rotifer Brachionus rotundiformis. Environ. Pollut., 237:50-64.

Matsukawa, R.; Dubinsky, Z.; Kishimoto, E.;Masaki, K.; Masuda,Y.; Takeuchi, T.; Chihara, M.; Yamamoto, Y.; Niki, E. and Karube, I. (1997). A comparison of screening methods for antioxidant activity in seaweeds. J. Appl. Phycol., 9:29-35.

Messyasz, B. and Rybak, A. (2010). Abiotic factors affecting the development of Ulva sp. (Ulvophyceae, Chlorophyta) in freshwater ecosystems. Aquat. Ecol., 45:75-87. https://doi.org/10.1007/s10452-010-9333-9.

Mohan, K.; Ravichandran, S.; Muralisankar, T.; Uthayakumar, V.; Chandirasekar, R.; Seedevi, P.; Abirami, R.G. and Rajan, D.K. (2019). Application of marine derived polysaccharides as immunostimulants in aquaculture: A review of current knowledge and further perspectives. Fish. Shellfish Immunol., 86:1177-1193. https://doi.org/10.1016/j.fsi.2018.12.072.

Nagraj, S. R. and Osborne, J. W. (2014). Bioactive compounds from Caulerpa racemosa as a potent larvicidal and antibacterial agent. Frontiers in Biology, 9 (4): 300-305. https://doi.org/10.1007/s11515-014-1312-4. 
Ortiz, J.; Romero, N.; Robert, P.; Araya, J.; Lopez-Hernández, J.; Bozzo, C.E.; Navarrete, C.E.; Osorio, A. and Rios, A. (2006). Dietary fiber, amino acid, fatty acid and tocopherol contents of the edible macroalgaes Ulva lactuca and Durvillaea antarctica. Food Chemistry, 99:98-104. https://doi.org/10.1016/j.foodchem. 2005. 07.027 .

Osman, M.E.H.; Abushady, A.M. and Elshobary, M.E. (2010). In vitro screening of antimicrobial activity of extracts of some macroalgae collected from Abu-Qir bay Alexandria, Egypt. Afr. J. Biotechnol., 9:7203-7208. https://doi.org/10.5897/ AJB09.1242.

Oumaskour, K.; Boujaber, N.; Etahiri, S. and Assobhei, O. (2012). Screening of antibacterial and antifungal activities in green and brown algae from the coast of Sidi Bouzid (El Jadida, Morocco). Afr. J. Biotechnol., 8(7): 16831-16837. https://doi.org/10.5897/AJB11.3761.

Pierre, G.; Sopena, V.; Juin, C.; Mastouri, A.; Graber, M. and Maugard, T. (2011). Antibacterial activity of a sulfated galactan extracted from the marine alga Chaetomorpha aerea against Staphylococcus aureus. Biotechnol. Bioprocess Eng., 16:937-945. https://doi.org/10.1007/s12257-011-0224-2.

Praiboon, J.; Chirapart, A. and Soisarp, N. (2017). Principle and biological properties of sulfate polysaccharides from seaweed. In: "Marine Glycobiology Principles and Applications.” SeKwon, K. (Ed.). CRC Press Taylor \& Francis Group: Boca Raton, FL, USA, pp. 85-120.

Prieto, P.; Pineda, M. and Aguilar, M. (1999). Spectrophometeric quantitation of antioxidant capacity through the formation of a phosphomolybdenum complex: specific application to the determination of vitamin E. Anal. Biochem., 269:337-341. http://hdl.handle.net/10396/10963.

Princely, S. and Dhanaraju M.D. (2017). Assessment of phytochemical constituents, in vitro antimicrobial and antioxidant potential of ulva extracts from Vishakhapatnam coast. Asian J. Pharm. Clin. Res., 10(8): 87-95. http://dx.doi.org/10.22159/ ajpcr. 2017.v10i8.18582.

Radhika, D.; Veerabahu, C.; Priya, R.; Mohaideen, A. (2014). A comparative study of bio potential of crude and fractionated extracts of some sea weeds from Tuticorin coast. Int. J. Phytopharmacol., 5(1):27-30.

Rajauria, G.; Jaiswal, A.K.; Abu-Gannam, N. and Gupta, S. (2013). Antimicrobial, antioxidant and free radicalscavenging capacity of brown seaweed Himanthalia elongata from western coast of Ireland. J. Food Biochem., 37:322-335. https://doi.org/10.1111/j.1745-4514.2012.00663.x.

Ratana-arporn, P. and Chirapart, A. (2006). Nutritional evaluation of tropical green macroalgaes Caulerpa lentillifera and Ulva reticulata. Kasetsart J. (Nat. Sci.), 40:7583.

Rupérez, P.; Ahrazem, O. and Leal, J.A. (2002). Potential antioxidant capacity of sulphated polysaccharides from the edible marine brown seaweed Fucus vesiculosus. J. Agric. Food Chem., 50:840-845.

Saunders, G.W. (2005). Applying DNA barcoding to red macroalgae: a preliminary appraisal holds promise for future applications. Phil. Trans. R. Soc. B., 360: 18791888. https://doi.org/10.1098/rstb.2005.1719. 
Shi, Q.; Wang, A.; Lu, Z.; Qin, C.; Hu, J. and Yin, J. (2017). Overview on the antiviral activities and mechanisms of marine polysaccharides from seaweeds. Carbohydr. Res., 453-454:1-9. https://doi.org/10.1016/j.carres.2017.10.020.

Silva, M.; Vieira, L.; Almeida, A.P. and Kijjoa, A. (2013). The marine macroalgae of the genus Ulva: Chemistry, biological activities and potential applications. J. Oceanogr. Mar. Res., 1(1):1-6.

Stirk, W.A.; Schwalb, A.N.; Light, M.E.; Medková, J.; Lenobel, R. and Strnad, M. (2003). Potential medicinal value of some South African seaweeds. South Afr. J. Bot., 69(4):462-8.

Tamura, K. and Nei, M. (1993). Estimation of the number of nucleotide substitutions in the control region of mitochondrial DNA in humans and chimpanzees. Molecular Biology and Evolution 10:512-526. https://doi.org/10.1093/oxfordjournals. molbev.a040023.

Temple, N.J. (2000). Antioxidants and disease: more questions than answers. Nutr. Res., 20:449-459.

Yang, J.J.; Yu, D.C.; Ma, Y.F.; Yin, Y. and Shen, S.D. (2019). Antioxidative defense response of Ulva prolifera under high or low temperature stimulus. Algal Res., 44:101703. https://doi.org/10.1016/j.algal.2019.101703.

Yuan, Y.V.; Bone, D.E. and Carrington, M.F. (2005). Antioxidant activity of dulse (Palmaria palmata) extract evaluated in vitro. Food Chem., 91:485-494.

Zeng, C. K.; Zhang, D. R. and Zhang, J. P. (1962). Flora of Chinese Economic Seaweeds. Beijing: Science Press. 